\title{
Use of ICT to Assist Students with Learning Difficulties: An Actor-Network Analysis
}

\author{
Tas Adam and Arthur Tatnall \\ School of Management and Information Systems, Victoria University, Australia \\ \{Tas.Adam, Arthur. Tatnall\}@vu . edu.au
}

\begin{abstract}
This paper reports on an investigation of the use of Information and Communications Technologies (ICT) to aid in the teaching of students with learning disabilities. The term 'learning difficulties' is used in reference to a heterogeneous group of students who are seen to have significant difficulties in the acquisition of literacy and numeracy skills. Other terms sometimes used in this context are 'learning disabilities' and 'special needs'. The study involved participant observation of the use of ICT in two outer suburban Melbourne Special Schools, and an investigation of the role and impact of Education Department policies on these school environments. Research at the two Special Schools revealed that use of ICT can have a very beneficial impact on these students by improving their self esteem and facilitating their acquisition of useful life skills. The study was framed by the use of actor-network theory.
\end{abstract}

Keywords: Information and Communications Technologies, Actor-Network Theory, Learning Difficulties, Special Schools, Students with Special Needs.

\section{Students with Learning Difficulties}

A significant number of students with learning disabilities, or special needs, require assistance and support in their learning. The introduction of Information and Communications Technologies (ICT) and use of the Internet have played a major part in shaping the knowledge and skills of these students. Assistive technology has introduced awareness for both educators and students and for the past decade there has been a growing effort in the design and development of ICT-based platforms to enhance the learning outcomes of these students $[1,2]$.

The study described in this paper involved participant observation in two outer suburban special schools in Melbourne, and in addition examined the role and impact of Education Department policies on these school environments [3]. The study also identified different categories of students with special needs, ranging from physical disabilities to mainstream students who have the need to maintain some continuity with their studies while temporarily placed in a hospital.

One of the problems in working in this area is terminology, with the terms: Learning Difficulties, Children at Risk, Special Needs and Learning Disabilities all being used in different countries and different contexts to describe these children. In this paper the term Learning Difficulties (LD) will be used to cover all of these other 
terms [4]. The definition for the term Learning Difficulties that is used in Australia is similar to that used in the USA:

A generic term that refers to a heterogeneous group of students who have significant difficulties in the acquisition of literacy and numeracy and who are not covered in the Commonwealth's definition of a student/child with a disability... Learning disability is believed to be a difficulty that is intrinsic to the individual and not a direct result of other conditions or influences [5].

Given the complexity of the definition of learning difficulties, one way to represent the differences is with the following Venn diagram where the term Learning Difficulties is used to refer to a large group of children who need extra assistance with schooling and Learning Disabilities refers to students who constitute a small sub-group that exhibit severe and unexplained problems.

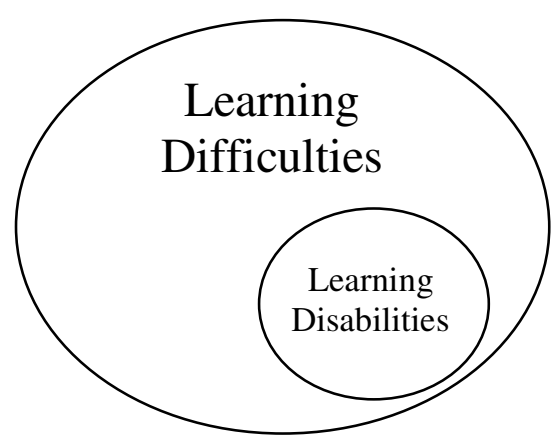

Fig. 1. Learning Difficulties and Learning Disabilities

Although policies have existed for some time in many countries to integrate students with learning difficulties into the mainstream classroom, this has not always provided the best learning environment for these students [6]; hence the need for some Special Schools. Bulgren [7] and Agran [8], support the view that some students with $\mathrm{LD}$ required an alternative approach to their learning and numerous 'integration' or 'remedial' programs have proved inefficient towards the total learning of this group of students. The literature also shows that in some selected fields, for example in mathematics and social studies, specialist instruction has been applied to this group of individuals with little success.

\section{A Case Studies of Two Melbourne Special Schools}

\subsection{Special School-A}

School-A is a purpose built 'Specialist School' providing a range of educational programs for students with special learning needs including global development delay, autism spectrum disorder, physical, social and emotional disabilities. It is located in 
Melbourne's north-west and is one of over 80 Government funded Specialist School Facilities in Victoria.

In addition to delivering the key learning areas as part of the curriculum the school provides a broad range of programs that are designed to further enhance the independence of its students. Some of the programs include Augmentative Communication, Work Education, Outdoor Education, Bike and Road Safety Education, Music Therapy, Swimming and Hydrotherapy Programs, Riding for the Disabled, Home crafts, Recreation and Leisure and Health and Human Relations Programs. The school has around 90 students, 8 full-time and 3 part-time teaching staff, 15 part-time school support officers and 2 part-time administration staff. The students are quite diverse in their special needs, both physical and intellectual. In the early 2000s the school had limited ICT resources for their learning with several Acorn machines, but very few PCs. The majority of the software was based on the DOS operating system platform where graphics and sound quality were limited. The library had a PC that was used to allow the students' access to the Internet, and PCs were used predominantly to reinforce language and numeracy skills. By 2010 the Acorn computers had been replaced by PCs.

The list of computer skills as was evidenced by a student survey indicated some key programs were used to assist the students in their learning. The teaching staff were quite happy with these programs as they felt these were adequate for their students' needs. An examination of the school's technology policy and curriculum showed that the use of ICT was an integral part of the classroom teaching and learning. The school heavily relied on ICT policies and support from the Department of Education, both for network access and software supplies. The administration systems were also provided and supported by the Department.

A research project over several years investigated the infrastructure to set up links between different classes at the local level. Given the limited support and availability for video-conferencing by the Education Department's resources, the attempt was welcomed by relevant school staff. The students showed a tremendous level of enthusiasm and immediate engagement when they began to communicate via the webcams. The main issue was, as expected, the limited bandwidth from the Local Area Network. Another significant issue was the security constraints and filters that are imposed on the Education Department's VicOne Network. This matter was further investigated in the following year of the research, and it was discovered that the Education Department had found that video-conferencing was not very much in demand for Victorian schools, and hence its support was downgraded considerably.

\subsection{Special School-B}

The vision of this school community encompasses a commitment to achieving excellence in education for students with additional learning needs through a curriculum which integrates learning technologies with best practice in teaching and learning. The values embraced by the school community are: Respect, Personal Best, Happiness, Cooperation, and Honesty. These values are imbedded in the Student Code of Conduct and the Staff, Principal and School Council Codes of Practice. 
Located on two campuses in the northern suburbs of Melbourne, School-B is a day specialist school which caters for students with mild to moderate intellectual disability between the ages of 5 and 18 years. Students come from a wide geographical area and diverse socio-economic backgrounds. The school's junior annexe (on another site) provides three classrooms for students aged between 5 and 9 years of age. The school itself is situated in attractive, well maintained grounds with excellent facilities which include: a Technology Centre, fully equipped gymnasium, Healthy Living Centre, Art and Craft room, well-resourced library, modern playground equipment, four school excursion buses, computer networking across the school, multi-purpose room and shaded outdoor playing areas.

The school, with 71 teaching and ancillary staff, has an enrolment of approximately 250 students. Enrolment is dependent on eligibility criteria as determined by the Department of Education and Training. A significant number of teachers at the school have post-graduate qualifications in special education. School-B supports integration into and from mainstream schools. Support services available to parent/carers and students include social workers, guidance officers, speech therapists and visiting teacher services.

The implementation of the Early Years Literacy and Numeracy Program at Junior and Middle school levels has increased opportunities for improved student skills in literacy and numeracy. The Secondary School has a focus on the enhancement of student engagement through Middle Years strategies based on improved Literacy and Numeracy, and the introduction of a 'Thinking Curriculum'. The Transition Centre caters for students sixteen to eighteen years of age with the focus on the development of dual pathways to cater for the diverse needs of the students. The school has a high level of commitment to a curriculum which integrates learning technologies with best practice in teaching and learning in order to enhance educational outcomes for its students. The Technology Centre has facilitated important opportunities for the school's students, its staff and for staff from neighbouring schools [9].

In 2006 School-B introduced a number of social and networked learning activities and practices, with software such as Lumil, WordPressMU, ccHost, Urdit, Gregarius and Scuttle. This paper reports on some of the activities undertaken, technologies used and the progress made during this period. For the purposes of this research the individual items of social software used at School-B have been appraised separately, yet in practice these tools and technologies are complimentary and have been used concurrently. In fact, much of the power of social software is its interoperability. By using these tools the school expects its students to create and publish content and respond to the content creation of others. Created content can be aggregated to show progress and richness and depth of learning. Students can respond to the work of others, provide feedback and learn through their interactions with others online. Not only are the students learning, but they are also learning how to be independent learners [1].

Collaborative Web 2.0 technologies and practices strongly support effective knowledge management practices. By using open web-based standards, such as RSS and XML and open API web services, complimentary software can share data in rich and unique ways. In future years, interoperability may well be the key criteria for introducing new technologies and systems as teachers and administrators become more familiar 
with working in networked environments. In introducing the social software it was attempted to integrate with existing practices, using web-based tools and technologies to construct richer tasks for the students. For example, using web-based photo sharing, students and teachers tagged photos which were then used in student digital portfolios. By using this approach not only did they introduce the required skills and practices but the school also reduced the workload for teachers who had previously organised the resources for use in the previous student digital portfolios [1,9].

By looking at their existing curriculum they identified opportunities to use web collaboration. For example, they found that they could use the social media sharing website ccHost within their loop-based music creation topic. Having traditionally used the audio samples that came with the software, they discovered they could easily integrate online networked learning to increase learning outcomes. Now students can find audio samples based on tags, use these samples in their composition and then share their composition online, highlighting the samples that they used. Other students could then make derivative works by taking samples from the composition of others. The school has attempted to provide all of the social networking web services on their Intranet to ensure that the students' privacy and security can be carefully monitored.

\section{Actors and Networks: Actor-Network Theory}

Special Schools are complex socio-technical entities and research into their curriculum needs to take account of this complexity. A significant difficulty arises in framing research in a situation like this that involves both technological and human actors. When dealing with the related contributions of both human and non-human actors, actor-network theory [10-12] provides a useful framework. Actor-network theory (ANT) reacts against the idea that characteristics of humans and social organisations exist which distinguish actions from the inanimate behaviour of technological and natural objects, instead offering a socio-technical approach in which neither social nor technical positions are privileged.

The actors involved in the adoption of this technology to assist students with special needs include: students, parents, teachers, school principals, school ICT specialist teachers, the School Council, the Web, computers, Education Department policies, learning technology policy, the school environment, classroom environments, learning approaches and paradigms, delivery methods of instruction, engagement methods, thinking processes, technology infrastructure-bandwidth, curriculum, Internet resources, digital libraries and other schools.

In an ANT framework, actors are seen to contest and negotiate with each other in an attempt to influence the final outcome in a direction to their own liking. The Education Department, for example, might want ensure that all schools offer a similar level of service to students and to ensure their accountability. The parents of a student with LD, on the other hand, would want the best for their own child regardless of what was going on in other schools. The technology (both hardware and software) itself acts in the way it was designed, both intentionally and unintentionally, to act. 


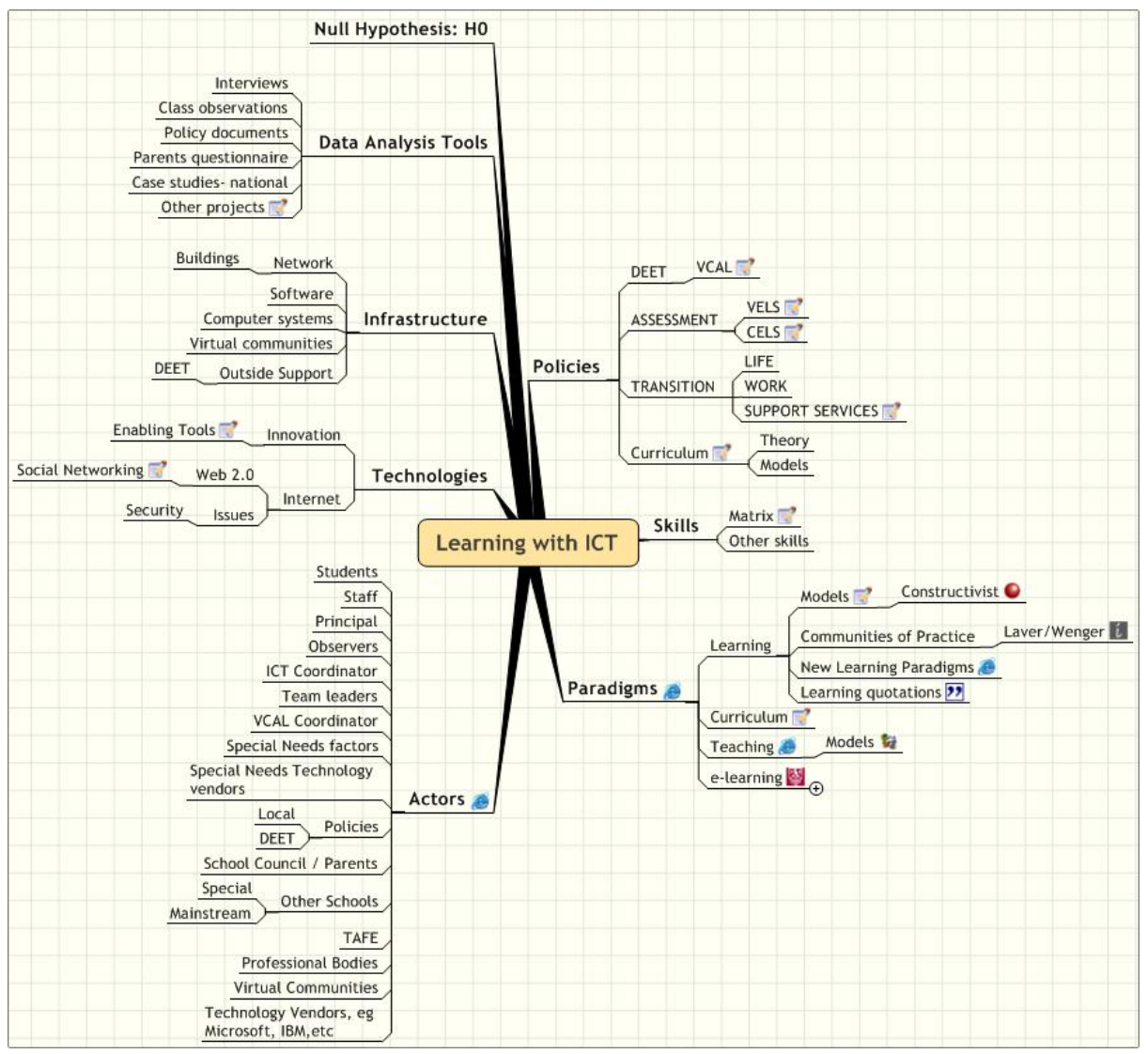

Fig. 2. Identification of the Actors

A major challenge to schools of this type is to get all these actors to form a common problematisation [10] of their task - to all see the problem in the same way. If this can be achieved then all the actors can work together to achieve a common goal, and ANT offers some ideas on how this might be achieved. ANT considers associations and interactions between human and non-human actors but its proponents make no claim that this approach can do any more than shed a little light on how a given approach is taken or technology is adopted. Despite this, we believe that if a researcher understands how the factors involved in the adoption of a new technology interact then it is possible to affect the outcome by assisting favourable interactions and doing one's best to reduce unfavourable interactions.

The concept of an actor underlies ANT, where an actor is the term used to represent any physical entity that has an effect on the phenomenon under investigation [10, 13]. An actor is considered as any entity able to associate texts, humans, non-humans and money [14]: "Accordingly, it is any entity which more or less successfully defines and builds a world filled by other entities with histories, identities, and interrelationships of their own" [14]. An actor is an abstraction which enables the analysis of 
situations where heterogeneous entities are encountered [13]. The purely social or technological approaches are essentialist and deterministic in nature, whereas ANT is designed to be anti-essentialist and non-deterministic. The concept of an actor allows sociologists to write about the situatedness of innovation and technology without the need to use demarcations separating the social from the natural; or sociological conventions from technological ones. The abstraction frees the analysis from the boundaries of disciplines, thereby allowing the observer to resist the need to reduce complex phenomena to a few well-defined political, social or technological categories [15].

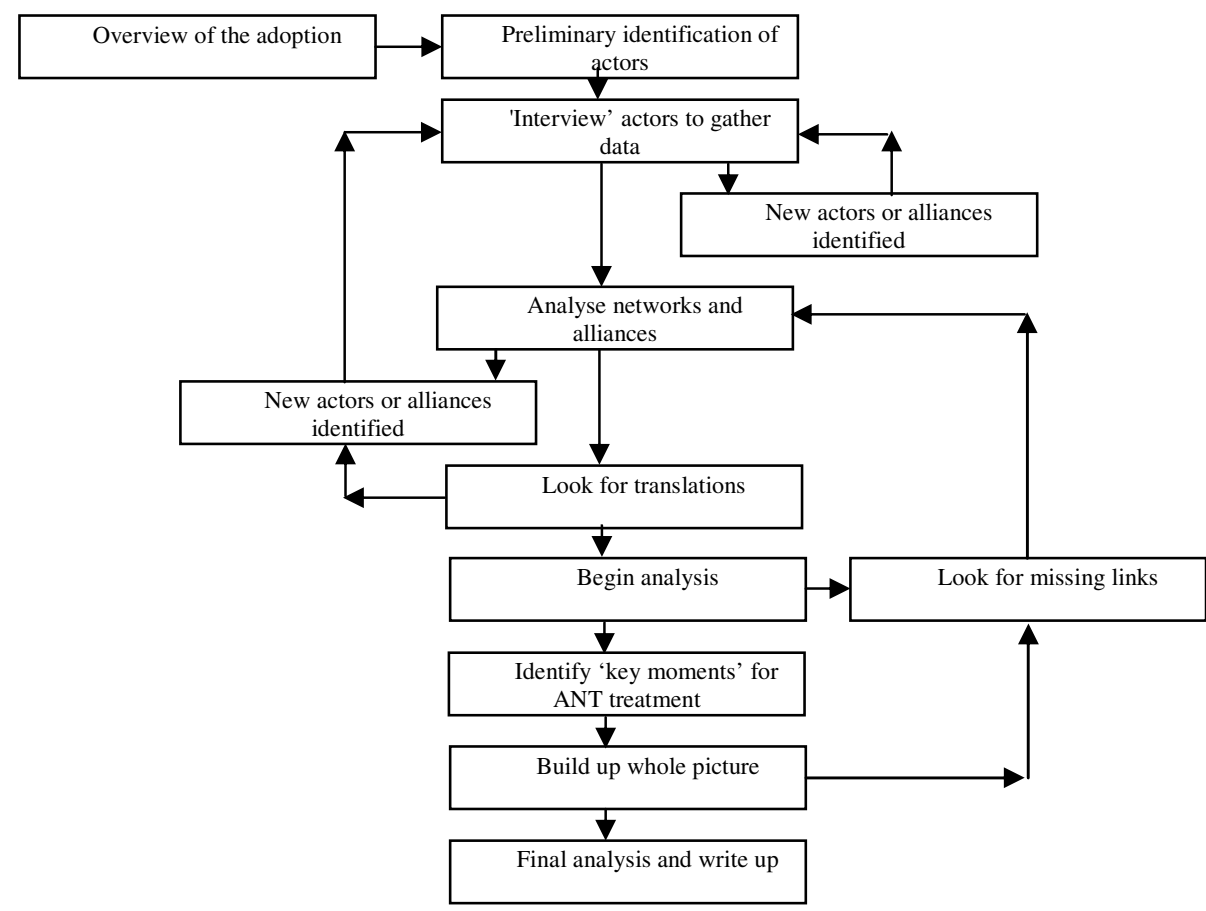

Fig. 3. The ANT Research Process [16]

The main method advice offered by Latour in conducting an ANT research project is to "Follow the Actors" [11], but this is just a beginning. When using ANT the research process that is followed is far from linear and not just simply a matter of collecting data, analysing the data then writing it up. The process could better be seen as an iterative one, something more like that shown in Fig 3 above $[16,17]$. After the actors have been identified and 'interviewed' and networks of interactions between actors have been examined, the process continues to look for new actors and for how the technology may have been translated in the process of adoption. This figure attempts to illustrate something of the complexity and iterative nature of this process.

A good deal has been written on how ANT can be employed for socio-technical analysis. For example, Bigum [18] provides one interesting application of ANT, while 
Gilding [19] and Tatnall [20] also provide studies applying ANT to Education and Technology. Other examples include the studies of Hull [21], Law [22] and Walsham and Sahay [23]. More recently, the Queensland education department used ANT to investigate the impact of ICT in education [24, 25]. There are also recent examples of how ANT was used to analyse ICT infrastructure [26], financial institutions [27], callcentres [28] and on-line communities [29].

\section{Data Collection and Analysis}

For this research data was collected by attending and observing specific classes at these two schools on a regular basis. The first school was visited in 2003 and 2004 while the second was approached in 2005 and 2006. At School-B a specific project was set up by the school community, and the researcher was asked to take part in this through the assistance and co-operation of the Principal, as well as several key staff members. He became a team member and worked very closely with a class of senior students who were referred to as the Transition Group which showed varied ability and special needs or handicap. The project was called the 1-2-1 project and it was a significant step to providing the state of the art 'hands-on' resources to the group. For example, each student was provided with a Laptop to use and carry in class or to take home. The research was conducted in a very supportive manner. It should be noted that funding was also provided by the school of Information Systems at Victoria University and this allowed an analysis of the ICT infrastructure and provided several PDAs along with Dragon digital voice recording equipment. The school gave access to all available data at the time. The students were assessed in the main domains of knowledge and, in particular, data were provided to the research that showed an analysis of the key indicators for each class in ICT for teaching and learning. The 1-2-1 project was later extended to include many other groups in the middle of the school.

The original concept by now had gone beyond what anyone could have imagined with the introduction of Social Networking programs. The main observations highlighted the strong self-esteem and engagement by the groups of students. Other data were collected by the ICT coordinator to determine the background of teachers in ICT. In fact at this time, the Victorian Government introduced the 'ICT Potential Project' with the aim to diagnose the various ICT skills of teachers in schools and how these were applied in the curriculum. The researcher became an actor himself in this process whilst endeavouring to discover the impact and existence of other actors and actor-networks or ensembles. Using participant observation the researcher became an observer and participant at school meetings and regular class sessions that involved technology and computer programs through the Web. In addition to observations he interviewed these actors and collected relevant documents in order to identify further actors and their networks.

The research found that there are several actors whose work is particularly important to the achievement of a good outcome in the school. Firstly, the ICT system, social software and networked learning activities must be appropriate and also they must be induced to co-operate with the students and teachers. This co-operation can be facilitated by another important actor: the ICT specialist teacher who should have 
both a good idea of what is required educationally, and also of the capabilities of students and teachers to understand and use the software and hardware. It does not take much observation to see that the students are readily willing to work with ICT and enjoy using it: they do not need much convincing. Hopefully the other teachers can also see the benefits of using ICT, even if they do not use it themselves, but this is not always the case and this is where another important actor comes in. The School Principal is crucial to the success of this program as without the Principal's support, many things will not be possible. One area where the Principal can be of considerable use is in influencing, or perhaps coercing other teachers to support the program. Another is with the provision on funds for hardware and software purchases and the provision of time for the ICT coordinator to find out about new products and services. One thing to come out very clearly from our research is the importance of the school Principal and without an actively supportive Principal, there is little chance that the project of using ICT with these children will succeed.

\section{Conclusion}

Our research shows that there is no doubt that the use of ICT can have a beneficial impact on the education of children with learning difficulties. It can do this both by improving their self esteem by providing the means by which they can achieve something they consider worthwhile and also by facilitating the acquisition of useful life skills. To achieve this result however, the actors involved, both human and nonhuman must be induced to work together to produce the desired result. In this, the role of one particular actor is crucial: the School Principal. This actor has the power to provide appropriate funds when required, to coerce his colleagues into working towards a common goal, to encourage the school ICT specialist to make good use of the software and make it easy to use and to reassure the parents that the school is doing its job well. The use of actor-network theory as a research framework facilitates the holistic analysis of schools such as these and how they operate.

\section{References}

1. Adam, T., Tatnall, A.: Using ICT to Improve the Education of Students with Learning Disabilities. In: Kendall, M., Samways, B. (eds.) Learning to Live in the Knowledge Society, pp. 63-70. Springer, New York (2008)

2. Adam, T., Tatnall, A.: Building a Virtual Knowledge Community of Schools for Children with Special Needs. In: Abbott, C., Lustigova, Z. (eds.) Information Technologies for Education and Training (iTET), pp. 185-193, ETIC Prague. Charles University, Prague (2007)

3. Adam, T.: Determining an e-learning Model for Students with Learning Disabilities: An Analysis of Web-based Technologies and Curriculum. In: Management and Information Systems, Doctor of Philosophy. Victoria University, Melbourne (2010)

4. Commonwealth of Australia: Literacy for All: The Challenge for Australian Schools. Commonwealth Literacy Policies for Australian Schools. Australian Schooling Monograph Series No. 1/1998, vol. 2010. Commonwealth of Australia, Canberra (1998)

5. Rivalland, J.: Definitions \& identification: Who are the children with learning difficulties? Australian Journal of Learning Difficulties 5, 12-16 (2000) 
6. Shaw, S., Grimes, D., Bulman, J.: Educating Slow Learners: Are Charter Schools the Last, Best Hope for Their Educational Success? The Charter Schools Resource Journal 1 (2005)

7. Bulgren, J.: Effectiveness of a concept teaching routine in enhancing the performance of LD students in secondary-level mainstream classes. Learning Disability Quarterly 11 (1998)

8. Agran, M.: Teaching Self-Instructional Skills to Persons with Mental Retardation: A Descriptive and Experimental Analysis. Education and Training of the Mentally Retarded 21, 273-281 (1997)

9. Adam, T., Tatnall, A.: ICT and Inclusion: Students with Special Needs. In: Lloyd-Walker, B., Burgess, S., Manning, K., Tatnall, A. (eds.) The New 21st Century Workplace, pp. 7585. Heidelberg Press, Melbourne (2008)

10. Callon, M.: Some Elements of a Sociology of Translation: Domestication of the Scallops and the Fishermen of St. Brieuc Bay. In: Law, J. (ed.) Power, Action \& Belief. A New Sociology of Knowledge?, pp. 196-229. Routledge \& Kegan Paul, London (1986)

11. Latour, B.: Aramis or the Love of Technology. Harvard University Press, Cambridge (1996)

12. Law, J., Callon, M.: The Life and Death of an Aircraft: A Network Analysis of Technical Change. In: Bijker, W., Law, J. (eds.) Shaping Technology/Building Society: Studies in Sociological Change, pp. 21-52. MIT Press, Cambridge (1992)

13. Law, J.: Notes on the Theory of the Actor-Network: Ordering, Strategy and Heterogeneity. Systems Practice 5, 379-393 (1992)

14. Callon, M.: Techno-Economic Networks and Irreversibility. In: Law, J. (ed.) A Sociology of Monsters. Essays on Power, Technology and Domination, pp. 132-164. Routledge, London (1991)

15. Callon, M.: The Sociology of an Actor-Network: The Case of the Electric Vehicle. In: Callon, M., Law, J., Rip, A. (eds.) Mapping the Dynamics of Science and Technology, pp. 19-34. Macmillan Press, London (1986)

16. Tatnall, A.: Innovation Translation in a University Curriculum. Heidelberg Press, Melbourne (2007)

17. Tatnall, A.: Researching the Adoption and Implementation of Innovative Enterprise Information Systems. In: Cruz-Cunha, M.M., Varajao, J.E.Q., do Amaral, L.A.M. (eds.) Conference on ENTERprise Information Systems (CENTRIS), pp. 245-254. Universidade de Tras-os-Montes e Alto Douro, Ofir (2009)

18. Bigum, C.: Solutions in Search of Educational Problems: Speaking for Computers in Schools. Educational Policy 12, 586-596 (1998)

19. Gilding, T.: Student Construction of a Knowledge-based System as an Actor Network, School of Education, p. 198. Deakin University, Geelong (1997)

20. Tatnall, A.: Innovation and Change in the Information Systems Curriculum of an Australian University: a Socio-Technical Perspective, Doctor of Philosophy. Central Queensland University, Rockhampton (2000)

21. Hull, R.: Actor network and conduct: The discipline and practices of knowledge management. Organization 6, 405-428 (1999)

22. Law, J., Hassard, J.: Actor Network Theory and After. Blackwell Publishers, Oxford (1999)

23. Walsham, G., Sahay, S.: GIS for District-level Administration in India: Problems and Opportunities. MIS Quarterly 23, 39-65 (1999)

24. Simpson, N.: Studying Innovation in Education: the Case of the ConnectEd Project. In: Jeffery, P.L. (ed.) Australian Association for Research in Education (AARE 2000), Sydney (2000) 
25. Australian Government Department of Education, E.a.W.R.: Project to Improve the Learning Outcomes of Students with Disabilities in the Early, Middle and Post Compulsory Years of Schooling. Part 1: Research Objectives, Methodology, Analyses, Outcomes and Findings, and Implications for Classroom Practice Canberra (2007)

26. Cordella, A.: Information Infrastructure: An Actor-Network Perspective. International Journal of Actor-Network Theory and Technological Innovation 2, 27 (2010)

27. Iyamu, T., Roode, D.: The Use of Structuration Theory and Actor Network Theory for Analysis Case Study of a Financial Institution in South Africa. International Journal of Actor-Network Theory and Technological Innovation 2, 1-26 (2010)

28. Naidoo, T.R.: A Socio-Technical Account of an Internet-Based Self-Service Technology Implementation: Why Call-Centres Sometimes 'Prevail' in a Multi-Channel Context? International Journal of Actor-Network Theory and Technological Innovation 2, 15-34 (2010)

29. Zammar, N.: Social Network Services: the Science of Building and Maintaining Online Communities, a perspective from Actor-Network Theory. International Journal of ActorNetwork Theory and Technological Innovation 2, 49 (2010) 